\title{
Dignity and cost-effectiveness: analysing the responsibility for decisions in medical ethics
}

\author{
George S Robertson Department of Anaesthetics, The Royal Infirmary, Aberdeen
}

\section{Author's abstract}

In the operation of a health care system, defining the limits of medical care is the joint responsibility of many parties including clinicians, patients, philosophers and politicians. It is suggested that changes in the potential for prolonging life make it necessary to give doctors guidance which may have to incorporate certain features of utilitarianism, individualism and patient-autonomy.

The article by Dr Brooks, if taken seriously, might threaten the candid exchange of views on ethical dilemmas. For it breaks new ground in medical/ philosophical discussion not only in the extent but also in the manner of its distortions. There is a strong temptation to reply in kind to $\mathrm{Dr}$ Brooks's intemperateness and obloquy, his magniloquence and self-righteousness. But the subject deserves better. Audi partem alteram: in the sensitive field of medical ethics the strength of an argument will not be weakened by courteous listening and courteous response.

It is a pity that Dr Brooks has tried to make his own summary of my thoughts because, in getting it wrong, he has invalidated much of his subsequent argument. It is quite mischievous that he should bend my ideas until they fit into pigeon-holes of his own choosing utilitarianism and euthanasia.

My views can be condensed into two main points: (a) the individual has the right to express an opinion on his medical management, present or future, and (b) it is reasonable and sensible to attempt some definition of the limits of medical efforts at maintaining life in a variety of clinical contexts. While it may be right and proper to point out the possible implications of my proposals, this should not be done to the extent of obscuring the fundamental thesis.

The key to an understanding of the difference between my views and Dr Brooks's interpretation of my views is the question of intent. Are my proposals formulated with the intention of pursuing 'The greatest happiness for the greatest number'? As a matter of historical fact, the trial of Dr Leonard Arthur

\section{Key words}

Medical ethics; utilitarianism; euthanasia; dignity; costeffectiveness. was the catalyst. While refraining from passing an opinion on the ultimate legal judgement, I expressed concern at our apparent unpreparedness for dealing with ethical dilemmas in general. I then went on to explore precedents which might offer help in approaching the dilemmas of dealing with senile patients. One intention was to attempt an interpretation of the attitude of elderly people themselves. Subsequent events and correspondence have strengthened my opinion that sizeable numbers of the elderly are afraid of senility - nothing new in that - and they wish to have this fear recognised. Most importantly, they see a written expression of wish as a means of alleviating their fear and also permitting them some expression of opinion concerning future medical care. Thus my primary intention was to explore the possible means of giving expression to such opinions and assessing their admissibility in the clinical setting.

An obvious corollary is indeed the matter of the resource consequences of ignoring individuals' requests to be spared the excesses of medical treatment. Any reasonable reading of my arguments makes it clear that utilitarian considerations are entirely secondary and almost fortuitous. In terms of the motive for my proposals they are quite irrelevant. Dr Brooks admits that I intended my article to be about 'living wills', and the transmutation to utilitarianism must have been made as an excuse for getting across a message based upon a totally different set of arguments. The message - that utilitarianism is a morally unsuitable basis for making ethical decisions is not without substance as a philosophical tenet, and this will be discussed later.

My second theme has been the difficult question of 'when to stop'. Here, Dr Brooks is closer to reality in advocating the Hippocratic/'individualistic' approach to the solution of ethical problems. However, many, including myself, see the need to enumerate those factors which will minimise the arbitrariness of the individualistic approach. This is the point at which the advances of modern medicine oblige us to ask if we should change the way we apply the Hippocratic principle. Because of the virtual absence of guidelines on how specific clinical dilemmas should be faced, a common medical attitude is the sinister 'I have my own ways of solving the problem' or the pretentious 'I must 
judge for myself the merits of each case'. Hilfiker (1) is disarmingly candid: 'The problem is simply too difficult for me as a single human being to face in a conscious way,' and 'Because we have ignored the frequency with which these situations arise and their tremendous ethical importance, we force the physician into making profound ethical choices unprepared'. The individual doctor has to act, then, in his own private way. There are many anecdotes to support my impression that doctors in Britain practise something approaching active euthanasia much more often than many would admit or recognise. The current lack of guidance breeds a legal and moral uncertainty which in turn may encourage personal 'solutions' based upon illconsidered criteria, intuition or frank utilitarianism and expedience.

Dunea in When to Stop Treatment (2) employs the Report of the US President's Commission on Ethical Problems in Medicine to support the need for guidelines. Of the report he states 'Its conclusions, though often tentative, will serve to open a dialogue on a sensitive topic ... $\therefore \mathrm{He}$ concludes that '. . . we are prisoners in a moral vacuum, and . . . a debate on these issues may be agonising but is inescapable'.

Dr Brooks is, of course, entitled to air his fears of the move, as he sees it, towards utilitarianism in problem areas of medical ethics. However, whilst he acknowledges the stupidity of endless efforts at maintaining life, he is clearly unwilling to compromise on the individualistic approach. If we are to make progress through the maze of ethics, it will be necessary for more doctors and philosophers to come off the fence - to declare their hand. If a consensus is desirable (but some might see this as a threat to clinical freedom) then it will involve compromise. It may be argued that one cannot compromise on matters of principle, but such arguments constitute much of the driving force in extreme political and religious groups. In the real world, compromise, carefully and tolerantly argued, is a stabilising influence.

Dr Brooks acknowledges that 'The utilitarian approach has much validity when it deals with questions of resource allocation between different groups of patients'. However, he goes on to say that it is wrong to mix political macro-financial decisions with clinical micro-finance. I believe this to be mistaken on two counts. Firstly, at both levels, clinical care is inexorably linked with finance, and the political decisions on major allocations will only be as good as the information fed to political advisers. Thus someone, somewhere at the clinical level has to feed information into the medico-political chain. Secondly, the resource consequences of the care of each individual patient cannot be escaped by clinicians. It is no good simply passing the moral buck to, presumably, middle-grade medical managers whose judgement would then be made in greater medical ignorance. C P Snow called this "The doctrine of ethical neutrality' (3). He was referring to his atomic scientist colleagues who in the 1940s and 1950s had to square up to the dilemmas of research which could produce simultaneously the power to destroy cities and the power to heal men. In a speech in 1960 to the Americarp. Association for the Advancement of Science (3), Snow? said that many scientists objected to having 'the weigh $\overrightarrow{\overrightarrow{5}^{\prime}}$ of (moral) responsibility heaved upon them'. He went on 'There is, of course, one way to contract out. It hasbeen a favourite way for intellectual persons caught in $\overline{\bar{n}}$. the midst of waters too rough for them. It consists of the invention of categories . . . the division of moraf labour'. I would add that those who wish to opt out? should not complain when others try, however $\overrightarrow{0}$ inadequately, to grapple with the whole jigsaw puzzle and not only the individual pieces.

Are the questions of 'when to stop' and 'how much toํำ spend' to be left, then, to individual judgement, or dợ they merit attempts at definition, or are they deemed to be so inexorably linked with euthanasia as to beiv unthinkable? The last alternative is, in effect, a parody $\overrightarrow{\mathrm{T}}$ rather than an affirmation of the 'Right to Life'. I have argued elsewhere that the ethical basis for this becomes less tenable with each advance in medical care (4). $\vec{c}$

There are clear precedents for using objectiveD criteria, often derived from painstaking research, fo fํㅁ deciding when not to proceed with potentially life 3 saving medical treatment, on the simple grounds that ito will not work. Hence the value of defining 'brain death' in acute intensive care. Recent research o̊roo cardiopulmonary resuscitation (5) has shown that now possible to avoid altogether attempts cä resuscitation in clearly-defined categories of patients Is this utilitarianism, and is it euthanasia? I suggest it is neither: it is the sensible application of medicap knowledge.

Having dwelt largely upon the general issues of $D \vec{E}$ Brooks's paper, let me explore only one specific poin $\bar{B}$ which he has raised. This concerns what he calls the termination of 'the life of an individual, at least in par? because of the advantages accruing to others'. In this context I am not sure how far he sees the Hippocratio 'individualistic' approach to dilemmas as applying te the patient in isolation. There is more than a hint that the elderly patient should not be viewed within the context of family and friends. And yet this is how the ageing patient sees himself. Much of the fear of senility is not concerned with self, but rather with the unwitting exhibition of antisocial behaviour to those. whose sensibilities the 'real' self would want to protect N

In caring for ageing relatives our society could learp much from the study of certain Eastern societies, and an interesting feature of these societies is the philosophical acceptance of death by both the carers and the cared-for. No 'striving officiously' here, but rather the deliberate pursuit of dignity for its own sake In our own society, if the elderly wish to modify the impact of their future senility on their nearest and dearest, why not let them speak? Whether or not the have any relatives at all, it is clear that many of the elderly feel a sense of duty to society in general. Thus the accusation of utilitarianism should extend to the 
elderly themselves, for they are often the prime movers in attempts to influence events. To deny them this right is to deny that the wisdom of their years perhaps allows them, on occasion, to teach us doctors a lesson or two. One lesson is that our corporate medical guilt should have more to do with the process of dying and less with the loss of life itself.

\section{References}

(1) Hilfiker D. Allowing the debilitated to die. Facing our ethical choices. New England journal of medicine 1983; 308: 716-719.
(2) Dunea G. When to stop treatment. British medical journal 1983; 287: 1056-1057.

(3) Snow C P. The moral un-neutrality of science. Speech to the American Association for the Advancement of Science. 1960. In: Snow C P. The physicists. London: Macmillan, 1981; 181.

(4) Robertson G S. Dealing with the brain-damaged old dignity before sanctity. Fournal of medical ethics 1982; 4 : 173-179.

(5) Sowden G R, Robins D W, Baskett P F J. Factors associated with survival and eventual cerebral status following cardiac arrest. Anaesthesia 1984; 39: 39-43. 